\title{
Investigating Knowledge Management Factors Affecting Chinese ICT Firms Performance: An Integrated Framework
}

Weifeng Chen a, Marwan Elnaghi a \& Tally Hatzakis b

a Brunel Business School, Brunel University, Uxbridge, United Kingdom

b Transport for London, London, United Kingdom

\begin{abstract}
This paper sets out to investigate the critical factors of knowledge management (KM) considered to have an impact on the performance of Chinese information and communication technology (ICT) firms. An integrated KM framework is developed whereby it set to evaluate those critical factors and the role of $\mathrm{KM}$ on the performance of these firms. The findings from our 556 survey responses indicate that organizational culture and technology variables are found to form essential elements for knowledge management. This study confirms that the culture environment of an enterprise is central to its success in the context of China. Furthermore, it shows that a collaborated, trusted and learning environment within ICT firms will have a positive impact on their KM performance. In doing so, it provides the key to understanding $\mathrm{KM}$ in the Chinese context and also is recognizing the networking nature of the Chinese society which operates on the basis of "Guanxi". Although this research may seem limited to a developing country, however, the finding of this study has contributed to formulate some guidelines to develop KM strategies for the ICT firms from emerging economies.
\end{abstract}

\section{Keywords}

Knowledge Management (KM), ICT, Organizational Culture, Organizational Structure, KM System (KMS), KM Performance 


\section{Introduction}

Knowledge is one of the most strategic weapons for enterprises that can lead to sustained increase in profits. It is not surprising that many researchers have investigated enablers for fostering knowledge (Nonaka et al, 2000; Teece, 2000). For instance, knowledge enablers such as information technology, trust, organizational learning, and top management support, when aligned and integrated, can provide a comprehensive foundation to support knowledge management (Alavi et al., 2005; Michailova and Hutchings, 2006). Typically, these knowledge enablers are categorized from social and technical perspectives. However, although the appropriate enablers can enhance a firm's ability to create and share knowledge effectively, it does not insure that the firm is making the best decision of its resources or that it is managing the right knowledge in the right way (Lynam, et al., 2007; Hansen et al., 1999).

Knowledge management strategies are necessary for facilitating these enablers; they determine how to utilize knowledge resources and capabilities. In contrast to codification knowledge management strategy (Davenport et al. 1998; Swan et al. 2000), knowledge throughout Chinese society is shared primarily with fellow ingroup members. But business innovation and coordination can be hindered by ingroup rivalries, as well as by the few opportunities (such as quality circles) and incentives (such as suggestion bonuses) employees are offered to share their knowledge. According to Chow et al. (2000), employees in some privately owned Chinese firms have responded positively to changes in performance evaluations and rewards. Other enterprises, for instance, Lenovo, the largest IT enterprise in China (www.lenovo.com) have developed a knowledge-sharing ethos through systematic efforts to recruit, select, and socialize their workers (Teagarden et al., 2008). A focus on selecting and socializing individual workers tends to be more effective in China than in the U.S., whereas the development of a supportive company culture is more difficult due to the strong respect for tradition in and hierarchical structure of Chinese society.

In this paper, we develop an integrated framework of $\mathrm{KM}$ to evaluate the $\mathrm{KM}$ strategies and performance of Chinese ICT firms by investigating organizational culture, structure and information technology factors. The rest of this paper will be organized as follows. Section 2 reviews the prior research on KM in ICT firms and presents the proposed conceptual framework of this study. The research design and methodology guiding this study are explained in detail in section 3. Section 4 presents the data analysis results. Section 5 discusses the critical factors that impact on KM performances in Chinese ICT firms. Section 6 concludes the research findings, the limitations and indicates implications for future research.

\section{Integrated KM Framework Development}

Knowledge management strategies can be described along two dimensions reflecting their focus (Hansen et al., 1999). One dimension refers to explicit knowledge and 
emphasizes the capability to help create, store, share, and use an organization's explicitly documented knowledge. This dimension stresses codifying and storing organizational knowledge. Normally, knowledge is codified via information technology (Davenport et al. 1998; Swan et al. 2000). Codified knowledge is more likely to be reused. This strategy is referred to as codification strategy. Typically, system strategy is quite effective for sharing explicit knowledge. Knowledge based systems have been introduced for system strategy (Liao, 2002). However, it can also be employed for facilitating tacit knowledge. For instance, in case of consulting firms, system strategy can help keep track of individuals with particular expertise and enable a rapid communication (Bloodgood and Salisbury, 2001). Another dimension refers to tacit knowledge and emphasizes knowledge sharing via interpersonal interaction. The strategy as per this dimension emphasizes dialogue through social networks including occupational groups and teams (Swan et al 2000). It also stresses sharing through person-to-person contacts (Hansen et al 1999). This strategy attempts to acquire internal and opportunistic knowledge and share it informally (Jordan and Jones, 1997). Knowledge can be obtained from experienced and skilled people in this strategy. It can be referred to as personalization (human) human strategy. It would appear that human strategy is utilized for fostering tacit knowledge only. However, human strategy can be employed to sharpen explicit knowledge (Kidd, 1998). Table 1 summarizes the features of Codification and Personalization strategies.

\section{TABLE 1 GOES ABOUT HERE}

In this paper, an integrated $\mathrm{KM}$ framework is developed to examine the KM strategies of Chinese ICT firms by investigating the impact of organizational culture, structure factors, and Knowledge Management Systems (KMSs) on KM performance of these firms.

\subsection{Organizational Culture}

Organizational culture is essential for successful knowledge management (Davenport et al., 1998; Gold et al., 2001). Culture is a basic building block to knowledge management. A survey by Chase (1998) indicates that 80 percent of the people who participated in the survey recognize that culture is the most important factor for creating a knowledge-based organization. Therefore, culture must be considered when introducing knowledge management because it affects how an organization accepts and foster knowledge management initiatives. As a result, if knowledge management is to be an integrated aspect of how work gets done in an organization, it must become an integrated aspect of the culture (Ndlela and Toit, 2001). Hence, culture defines not only what knowledge is valued, but also what knowledge must be kept inside the organization for sustained innovative advantage. Creating a knowledge friendly culture, one of the most critical factors of success for a knowledge management (Ndlela and Toit, 2001; Lee and Kim, 2001; Davenport and Prusak, 1998).

Organizations should establish an appropriate culture that encourages people to create and share knowledge within an organization (Holsapple and Joshi, 2001; LeonardBarton, 1995). 


\section{Collaboration}

Effective knowledge management requires a collaborative culture (Gold et al., 2001; O'Dell and Grayson, 1999). Collaborative interactions such as open dialogue, social interaction, and coactivity can help create organizational knowledge. Exchanging knowledge among different members is a prerequisite for knowledge creation. Collaborative interactions foster this type of exchange by reducing fear and increasing openness to other members. Without established and aligned shared understanding among organizational members, little knowledge is ever created (Fahey and Prusak, 1998). Hedlund (1994) argued that knowledge creation should be facilitated by the availability of a shared understanding. Not surprisingly, many studies have recognized collaboration as a key enabler for knowledge creation (Nonaka and Takeuchi, 1995; O'Dell and Grayson, 1999). Therefore, we hypothesize:

\section{H1: Collaboration will have a positive effect on KM performance.}

\section{Trust}

Trust may facilitate open, substantive, and influential information exchange (Nelson and Cooprider, 1996, O'Dell and Grayson, 1999). When their relationships are high in trust, people are more willing to participate in knowledge exchange and social interactions (Nahapiet and Ghoshal, 1998). People seek advice from trusted colleagues to sharpen their understanding of the problems. Szulanski (1996) empirically found that the lack of trust among employees is one of the key barriers against knowledge transfer. The investment of trust among organizational members can be thought of as a leap of knowledge transfer (Nelson and Cooprider, 1996). The increase in knowledge transfer brought on by mutual trust results in knowledge creation. The exchange of knowledge is not amenable to enforcement by contract, and thus gives rise to a high level of risk and uncertainty. The presence of a high level of trust can reduce this risk (Nelson and Cooprider, 1996; Roberts, 2000). It could be expect this relationship to hold true:

\section{H2: Trust will have a positive effect on KM performance.}

\section{Learning}

Learning is the acquisition of new knowledge by people who are able and willing to apply that knowledge in making decisions or influencing others (Miller, 1996). Kanevsky and Housel (1998) argued that the amount of time spent learning is positively related with the amount of knowledge. Intellectual organizations seem to develop a deeply ingrained learning culture (Quinn et al., 1996). For successful knowledge creation, individuals should be encouraged to ask questions (Ndlela and Toit, 2001). Knowledge creation capacity is increased by various learning means such as education, training, and mentoring (Narasimha, 2000). The mere presence of 
traditional training and development activities may not be sufficient. Those organizations which are serious about knowledge creation need to support a continuous learning environment (Ndlela and Toit, 2001). Learning should happen at all levels of the organization structure. Individuals must be encouraged to ask questions, to challenge and to learn. This continuous learning opens up the possibility of achieving scale in knowledge creation. Nucor, which has been the most innovative steel company in the U.S., built a knowledge creation foundation by investing in continuous and multifunctional training programs (Gupta and Govindarajan, 2000).

Hence, we hypothesize:

\section{H3: Learning will have a positive effect on KM performance.}

\subsection{Organizational Structure}

The organizational structure within an organization may encourage or inhibit knowledge management (Gold et al., 2001; Nonaka and Takeuchi, 1995).

Organizations' structures should be organized so that they are close to the context for knowledge creation and are able to act for knowledge creation. It is important that organizational structure should be designed for flexibility so that they encourage creating and sharing knowledge across boundaries within the organization. This study focuses on two key structural factors such as centralization and formalization (Menon and Varadarajan, 1992). They are recognized as key variables underlying the structural construct. Moreover, their effects on knowledge management within organizations are widely recognized to be potent (Jarvenpaa and Staples, 2000).

\section{Centralization}

Centralization refers to the locus of decision authority and control within an organizational entity (Caruana et al., 1998). The concentration of decision-making authority inevitably reduces creative solutions while the dispersion of power facilitates spontaneity, experimentation, and the freedom of expression, which are the lifeblood of knowledge creation (Graham and Pizzo, 1996). Therefore, many researchers proposed that a centralized organizational structure makes it harder to create knowledge (Teece, 2000). For example, Zaltman (1986) noted that more knowledge is created in a less centralized organizational structure. Moreover, centralized structure hinders interdepartmental communication and frequent sharing of ideas due to time-consuming communication channels (Bennett and Gabriel, 1999); it also causes distortion and discontinuousness of ideas (Stonehouse and Pemberton, 1999). Without a constant flow of communication and ideas, knowledge creation does not occur. A decentralized organizational structure has been found to facilitate an environment where employees participate in knowledge building process more spontaneously (Hopper, 1990). Participatory work environments foster knowledge creation by motivating organizational members' involvement. Therefore, decreased centralization in the form of locus of authority can lead to increased utilization and creation of knowledge. For these reasons, some researchers argued that knowledgecentric firms should downplay the concentration of decision-making authority 
(Szulanski, 1996). It would be realistic then, to posit that when an organization is rigidly centralized, knowledge creation is low. Hence we propose the fifth hypothesis:

\section{H4: Centralization will have a negative effect on KM performance.}

\section{Formalization}

Formalization refers to the degree to which decisions and working relationships are governed by formal rules, standard policies, and procedures (Holsapple and Joshi, 2001). Knowledge creation requires flexibility and less emphasis on work rules (Bennett and Grbriel, 1999). The range of new ideas seems to be restricted when strict formal rules dominate an organization. The increased flexibility in an organizational structure can result in increased creation of knowledge. Knowledge creation also requires variation. In order to be more adaptable when unforeseen problems arise, an organization may accommodate variation in process and structure. This adaptability provides more options and allows rich stimulation and interpretation (Nevis et al., 1995). Low formalization permits openness and variation, which encourage new ideas and behaviours (Damanpour, 1991). Knowledge creation is also likely to be encouraged through unhindered communications and interactions (Bennett and Grbriel, 1999). Formality stifles the communication and interaction necessary to create knowledge. Lack of formal structure enables organizational members to communicate and interact with one another to get easy access to knowledge and its flow (Jarvenpaa and Staples, 2000). Hence, we hypothesize:

\section{H5: Formalization will have a negative effect on the KM performance.}

\subsection{Knowledge Management Systems (KMS)}

Information technology (IT) is widely employed to connect people with reusable codified knowledge, and it facilitates conversations. It qualifies as a natural medium for knowledge flow. Through the linkage of information technology in an organization, previously fragmented flows of knowledge can be integrated (Gold et al., 2001). Investments in information technology seem to be unavoidable to scale up knowledge management projects (Borghoff and Pareschi, 1997). Sophisticated knowledge management systems pay off because of their ability to reuse knowledge (Davenport et al., 1998; Hansen et al., 1999; Markus, 2001). Information technology is the enabler to managing knowledge effectively and for an organization to see its full benefits (Ndlela and Toit, 2001). Among technology related variables, this study focuses on information technology support (Stonehouse and Pemberton, 1999). Information technologies within an organization determine how knowledge is used and accessed (Leonard-Barton, 1995). Therefore, the support of information technology is essential for initiating and performing knowledge management. An organization should invest in a comprehensive infrastructure that can support the various types of knowledge activities (Gold et al., 2001). Currently, little empirical research has been conducted on information technology support for knowledge management in Chinese ICT firms. 
Information technology support means the degree to which knowledge management is supported by the use of information technologies (Gold et al., 2001). Many researchers have found that information technology is a crucial element for knowledge creation and transfer (Alavi and Leidner, 2001; Davenport and Prusak, 1998; Gold et al., 2001). Information technology affects knowledge in a variety of ways. First, information technology facilitates rapid collection, storage and exchange of data on a scale not practicable in the past, thereby assisting knowledge creation and the sharing process (Robert, 2000). It helps employees have easy access to the required knowledge (Ndlela and Toit, 2001). Second, a well-developed technology integrates fragmented flows of information and knowledge (Gold et al., 2001). This integration can eliminate barriers to communication among departments in organization. Third, information technology fosters all processes of knowledge creation and is not limited to the transfer of explicit knowledge (Bolisani and Scarso, 1999). For instance, InfoTEST's Enhanced Product Realization (ERP) project employs electronic whiteboarding and videoconferencing to enhance exchanges of tacit knowledge (Riggins and Rhee, 1999). Information technology upholds collaborative works, communication, searching and accessing, and systematic storing (Gold et al., 2001; Ndlela and Toit, 2001). The current technology can support creation and sharing of knowledge in a cost cutting way (Coleman, 1999). It may be built with knowledge-oriented tools such as Lotus Notes and the World Wide Webbased intranet. Another possible technology infrastructure is desktop computing and communication. A capable, networked PC on every desk, or in every briefcase, with standardized personal productivity tools and software may help exchange knowledge (Davenport et al., 1998). Thus, it can be suggested that knowledge management is more likely to succeed if a broader technology infrastructure is adopted. Therefore, the first hypothesis of this paper is

\section{H6: KMS will have a positive effect on KM performance.}

In sum, the conceptual framework developed for this study as shown in Figure 1.

\section{FIIGURE 1 GOES ABOUT HERE}

Methods for measuring organizational performance in knowledge management can be categorized into four groups: financial measures (Bierly and Chakrabarti, 1996), intellectual capital (Sveiby, 1997), tangible and intangible benefits (Simonin, 1997), and balanced scorecard (Kaplan and Norton, 2000). Financial measure is traditional method for organizational performance. For this research, KM performance are assessed by the use of global output measures such as market share, profitability, growth rate, innovativeness, successfulness, and the size of business in comparison with key competitors (Drew, 1997).

\section{Research Methodology}

The data samples selected for this research are from the listed companies from ICT industry in the China Enterprise Confederation (http://www.cec-ceda.org.cn/english/). 
The reason of selecting the companies in the ICT industry is that those firms are more active in knowledge management and product innovation comparing to other industries. The survey respondents are the managers and knowledge workers (Drucker, 1959) in the selected companies. The knowledge workers in this study include middle managers and employees from R\&D departments of the selected Chinese companies, who played key roles in managing knowledge. According to (Nonaka and Takeuchi, 1995), top management clarifies the vision for a company while front-line workers down in the trenches look at reality. The gap between vision and reality is narrowed by middle managers who arbitrate between top management and front-line through creating middle range business and product concepts. Middle managers are positioned at the intersection of the vertical and horizontal flows of knowledge. Employees in R\&D departments are typical knowledge workers, who develop and use knowledge in their workplace.

As the main research method, online survey was chosen. Online surveys provide quick, inexpensive, efficient, and accurate means of assessing information about the population (Dillman, 2000). Following Dillman's four stage piloting process, the researcher constructed two versions(Chinese and English) draft survey questionnaires using word processor and developed the online prototype, which went through two rounds of review with researchers (Chinese and English) in Brunel University to ensure question completeness, efficiency, relevancy and format completeness. Following that, the researcher used "think out loud" protocols with retrospective interviews to ask some people who are not involved in the research to complete the survey. These cognitive pre-tests resulted in language simplification on the invitation and survey questions, changes in sequencing, and feedback on the look and feel of the survey. After the prototype was updated once more, an invitation to review the survey was sent to the interviewees attended the case studies. 20 people completed the survey and 10 people provided feedback to varying degrees of detail. This pre-testing produced an array of technical testing changes to privacy and confidentiality language and requirements, numerous recommendations for question wording, inconsistencies among questions and elimination of several questions. After the survey is updated again according to the recommendations from those interviewees in Chinese companies, the main survey was active online. After 2 weeks since the first round of massive emailing, we started the first follow-up. While sending follow-up questionnaire, the cover letter was adjusted, and explained more on the study's social usefulness, the reason why respondent is important, and the confidentiality of the data. Accompanied with the main web-based survey, the researcher also contacted the respondents with more than 300 telephone calls and 30 personal visits to the companies to maximize the survey response from the first questionnaire follow-up.

\section{Data Analysis}

The survey was sent to a total of 2500 respondents electronically. Completed surveys were received from 556 individuals. 208 emails were received claiming that they were unable to participate in the survey due to various reasons such as having left the 
company or on leave. Therefore, an overall response rate of $22.2 \%$ was achieved (556/2500). This was a reasonable response rate given that this is an online survey and was fairly lengthy ( 7 questions with matrix, 2 pages).

This paper has adopted regression analysis to test the hypotheses. Table 2 provides the summary of the frequency distribution of survey results. In general, the results of the study reveal positive. The majority of the respondents (61\%) acknowledged high level collaboration between colleagues. 56\% state that there is a willingness to accept responsibility for failure. When respondents were asked if they have reciprocal faith in their colleagues' ability and intentions, the majority (58\%) agreed. In particular, 69.1 percent believed that they have reciprocal faith in their colleagues' decisions toward organizational interests rather than individual interests, according to the results, which suggest that Chinese enterprises today have developed collaborative culture based on trust between co-workers. Regarding organizational learning, 69\% agree that their company provides various formal training programmes for performance of duties. $67 \%$ agree that their company encourages them to attend seminars, symposiums, etc. to learn more knowledge and skills. The majority $(77.7 \%)$ are satisfied with the contents of job training and self-development programmes indicating that Chinese enterprises today are investing much effort into speeding up the knowledge acquisition process.

\section{TABLE 2 GOES ABOUT HERE}

It is predicted that centralized and formalized organizations lack flexibility and their management strategy will have a negative impact on knowledge management. According to the survey results, the fact that $85 \%$ responded that they are not allowed take action without a supervisor in their company and $70 \%$ disagree that they can make decisions without approval indicate that Chinese organization is very centralized in terms of organizational structure. This finding is consistent to the literature. However, the responses regarding organization formalization are not significant in this research. The fact that 70 percent of the participants stated that their respective organizations provide various knowledge sharing tools implies reasonable awareness of the importance of spreading knowledge by the management in Chinese firms. The responses of organizational performance (43\%) are not impressive in general. However, nearly $60 \%$ agree that their company is more innovative compared to key competitors suggesting reasonable awareness of the importance of innovation in Chinese ICT enterprises.

Table 3 demonstrated the correlation analysis results of all the variables of the conceptual framework. 1-tailed Pearson correlation method was used to test the correlation between variables.

\section{TABLE 3 GOES ABOUT HERE}

The variables are: Collaboration (V1); Trust (V2); Learning (V3); Centralization (V4); Formalization (V5); IT support (V6); Organizational performance (V7) 
Table 4 below presents the regression results.

\section{TABLE 4 GOES ABOUT HERE}

According to Table 4, organizational culture variables (Collaboration, Trust and Learning) and IT support have positive significant impact on KM performance. Organizational structure variable Centralization has negative significant effect on KM performance. Table 5 below summarizes the test results of the hypotheses proposed in section 2 .

\section{TABLE 5 GOES ABOUT HERE}

\section{Discussions}

Consistent with Hurley and Hult's (1998) findings, the results indicate that collaboration inside Chinese ICT firms has a positive impact on KM performance $(\beta=.120, p<.01)$. It suggests that collaborative interactions are able to foster exchanging knowledge among people by reducing fear and increasing openness to other members. It can help to develop a shared understanding of an organization's external and internal environments through supportive and reflective communication. As stated in Section 2.1, Nahapiet and Ghoshal (1998) has mentioned that some open dialogue and social interaction have encouraged the knowledge workers to share ideas and experience and enabled the knowledge flow within and between organizations, which will help to create organizational knowledge. Our analysis results have shown the evidence that knowledge creation can occur in a collaborated organizational environment.

As hypothesized Section 2.2, trust among organizational members has positive significant effect on $\mathrm{KM}$ according to the results $(\beta=.383, \mathrm{p}<.01)$. The results suggest that trust is an important factor for knowledge sharing in Chinese organizational culture. When the relationships of those knowledge workers are high in trust, they are more willing to participate in knowledge exchange and social interactions (Nahapiet and Ghoshal, 1998). In the context of China, similar to social capital, Guanxi is ubiquitous in playing a fundamental role in daily life and relationships are created over long periods of time that are built on frequent exchanges (Michailova and Worm, 2003). Trust in Chinese enterprises starts from Guanxi and develops to achieve personal or organizational goals. While organizations may profit from the existence of Guanxi between organizational members, "Guanxi is a relationship between two people who are expected, more or less, to give as good as they get" (Hutchings and Murray, 2002). In a trusted environment, knowledge sharing and transfer will occur which will lead to better knowledge creation.

According to the data analysis results, the hypothesized relationship between organizational learning and KM performance is strongly supported. The path from learning to KM performance is positive and statistically significant $(\beta=.778, p<.01)$. 
This result suggests that Chinese ICT firms today are investing lots effort into encouraging organizational learning. As stated in Section 2.3, learning is the acquisition of new knowledge by people who are able and willing to apply that knowledge in making decisions or influencing others (Miller, 1996). The emphasis on knowledge acquisition of Chinese enterprises implies that they are still at the early stage of building up knowledge-based firms.

It was hypothesized that centralization has a negative impact on KM performance. The results confirmed that there are negative and statistically significant $(\beta=-.563$, $\mathrm{p}<.01$ ) associations between them. Consistent with Graham and Pizzo's (1996) findings, the concentration of decision-making authority inevitably reduces creative solutions while the dispersion of power facilitates spontaneity, experimentation, and the freedom of expression, which are the lifeblood of knowledge creation. Chinese organizations are traditionally centralized; this fact it will cause distortion and discontinuousness of ideas. In China, authority and seniority are highly respected and top-down decision making actually serves to work against sharing of knowledge. Without a constant flow of communication and ideas, knowledge creation rarely occurs. The results confirmed the negative impact of Chinese ICT firms' structural centralization.

Our results also suggest that having KMS will have significant positive impact on KM performance $(\beta=.451, p<.01)$. The results implicate that the IT support within Chinese ICT firms helps their employees have easy access to the required knowledge. Those KMSs have integrated fragmented flows of information and knowledge that it can eliminate barriers to communication among departments in organization.

\section{Conclusions}

According to this research findings, having an integrated Knowledge Management Systems in the Chinese ICT firms have positive influence on performance. The cultural environment of an enterprise is found to be central to its success in the context of China. The authors also found that a collaborated, trusted, and learning environment within enterprises will have a positive impact on their organizational performance. Adding further, collaborative interactions within Chinese ICT firms are able to foster exchanging knowledge among people by reducing fear and increasing openness to other members. It also helped people to develop a shared understanding about an organization's external and internal environments through supportive and reflective communication. Trust in Chinese firms started from "Guanxi" and developed to achieve personal or organizational goals. Realising further that in the trusted environment, the increased knowledge transfer will lead to better quality knowledge creation. It is worth pointiong out that Chinese ICT firms today are spending considerable effort on encouraging organizational learning. Whereby, in a learning environment, they developed cultural and social contexts to facilitate the transfer and dissemination of acquired technology. Their heavy investment on knowledge acquisition and dissemination has had a positive impact on performance. It worth noting that Chinese culture where authority and seniority are highly respected 
and top-down decision approach making it actually serves to work against sharing of knowledge. The centralized nature of Chinese organizations caused distortion and discontinuousness of ideas, which affected the flow of knowledge within and between subunits of an organization. Without a constant flow of communication and ideas, knowledge creation rarely occurs.

In conclusion, Knowledge Management System, in this paper, is measured from an IT support perspective, which focuses on IT service quality for KM. However, other information technology factors, such as, IT usage that have the possibility of affecting the KM processes. Therefore, to increase the explanation power of the research results, the authors propose that future research should investigate actual frequency of information technology. It acknowledged that this research is limited to Chinese ICT firms in mainland China. Hence, the generalizability from a China setting to other researchers in different countries may be questionable. Therefore, the results of this study may have to be carefully interpreted and further empirical research which involves data collection over diverse countries is needed.

\section{References:}

- Alavi, M., and Leidner, D. E. (2001) Knowledge Management Review: Knowledge Management and Knowledge Management Systems, Conceptual Foundations and Research Issues, MIS quarterly, 25 (1): 107 - 136

- Alavi, M., Kayworth,R.T., and Leidner, D.E. (2005) An Empirical Examination of the Influence of Organizational Culture on Knowledge Management Practices, Journal of Management Information Systems, 22(3): $191-224$

- Beckman, T. (1999) The current state of knowledge management. In Liebowitz J. (ed.), Knowledge Management Handbook. Boca Raton: CRC Press, FL, 1:1-22.

- Bennett, R., and Gabriel, H. (1999)Organizational factors and knowledge management within large marketing departments: an empirical study. Journal of Knowledge Management, 3(3): 212-225.

- Bierly, P., and Chakrabarti, (1996) A. Generic knowledge strategies in the U.S. pharmaceutical industry. Strategic Management Journal, 17(Winter): 123-135.

- Bloodgood, J. M., and Salisbury, Wm. D. (2001) Understanding the influence of organizational change strategies on information technology and knowledge management strategies. Decision Support Systems, 31(1): 55-69.

- Bolisani, E., and Scarso, E. (1999) Information technology management: a knowledge-based perspective. Technovation, 19(4): 209-217.

- Borghoff, U., and Pareschi, R. (1997) Information technology for knowledge management. Journal of Universal Computer Science, 3(8): 835-842.

- Caruana, A., Morris, M.H., and Vella, A.J. (1998) The effect of centralization and formalization on entrepreneurship in export firms. Journal of Small Business Management, 36(1): 16-29. 
- Chase, R. (1998) The people factor. People Management, 4 (2): 38 - 60.

- Chow, C.W., Deng, F.J., and Ho, J.L. (2000) The openness of knowledge sharing within organizations: A comparative study in the United States and the People's Republic of China. Journal of Management Accounting Research 12(1): 65-95.

- Coleman, D. (1999) Groupware: collaboration and knowledge sharing. In J. Liebowitz (ed.), Knowledge Management Handbook. Boca Raton: CRC Press, pp. 11:1-23.

- Damanpour, F. (1991) Organizational innovation: a meta-analysis of effects of determinants and moderators. Academy of Management Journal, 3: 220-227

- Davenport, T.H., and Prusak, L. (1998) Working Knowledge. Boston: Harvard Business School Press,.

- Davenport, T.H., De Long, D.W. and Beers, M.C. (1998), Successful knowledge management projects, Sloan Management Review, Winter: 43-57.

- Dillman, Don A. (2000). Mail and Internet Surveys: The Tailored Design Method. New York: Wiley.

- Drew, S. (1997) From knowledge to action: the impact of benchmarking on organizational performance. Long Range Planning, 30(3): 427-441.

- Drucker, P. (1959), The Landmarks of Tomorrow, Harper and Row, New York, NY, .

- Fahey, L., and Prusak, L. (1998), The eleven deadliest sins of knowledge management. California Management Review, 40(4): 265-276.

- Gold, A.H., Malhotra, A., and Segars, A.H. (2001) Knowledge management: an organizational capabilities perspective. Journal of Management Information Systems, 18(1): 185-214.

- Graham, A. B., and Pizzo, V. G. (1996) A question of balance: case studies in strategic knowledge management. European Management Journal, 14(4): 338-346.

- Gupta, A. K., and Govindarajan, V. (Fall 2000) Knowledge management's social dimension: lessons from Nucor steel. Sloan Management Review, 7180 .

- Hansen, M., Nohria, N. and Tierney, T. (March-April 1999). What's your strategy for managing knowledge? Harvard Business Review: 106-116.

- Hedlund, G. A (1994) model of knowledge management and the N-form corporation. Strategic Management Journal, 15(Summer): 73-90

- Holsapple, C. W., and Joshi, K.D. (2001) Organizational knowledge resources. Decision Support Systems, 31(1): 39-54

- Hopper, M. D. (May-June 1990) Rattling SABRE-new ways to compete on information. Harvard Business Review, 68(3): 118-125.

- Jarvenpaa, S.L., and Staples, D.S. (2000) The use of collaborative electronic media for information sharing: an exploratory study of determinants. Strategic Information Systems, 9: 129-154.

- Jordan, J., and Jones, P. (1997) Assessing your company's knowledge management style. Long Range Planning, 30(3), 392-398. 
- Kanevsky, V., and Housel, T. (1998) The learning-knowledge-value cycle. In G. Krogh, J. Roos, and D. Kleine (eds.), Knowing in Firms. Thousand Oaks, CA: Sage Publications, , pp. 269-284.

- Kaplan, R., and Norton, D. (September-October 2000) Having trouble with your strategy? then map it. Harvard Business Review, 167-176.

- Kidd, J.B. (1998) Knowledge creation in Japanese manufacturing companies in Italy: reflection upon organizational learning. Management Learning, 29(2): 131-146.

- Lee, J.H and Kim, Y.G. (2001) A stage model of organizational knowledge management: a latent content analysis. Expert Systems with Applications, 20: 299-311.

- Leonard-Barton. D. (1995) Wellsprings of Knowledge: Building and Sustaining the Sources of Innovation. Boston: Harvard Business School Press,.

- Liao, S. (2002) Problem solving and knowledge inertia. Expert Systems with Applications, 22: 21-31.

- Lynam, T., W. De Jong, D. Sheil, T. Kusumanto, and K. Evans. (2007) A review of tools for incorporating community knowledge, preferences, and values into decision making in natural resources management. Ecology and Society 12(1): 5 .

- Markus, M.L. (2001) Toward a theory of knowledge reuse: types of knowledge reuse situations and factors in reuse success. Journal of Management Information Systems 18(1): 57-93.

- Menon, A., and Varadarajan, R. (1992) A model of marketing knowledge use within firms. Journal of Marketing, 56: 53-71.

- Michailova, S. and Hutchings, K. (2006) National Cultural Influences on Knowledge Sharing: A Comparison of China and Russia, Journal of Management Studies, 43(3): 383-405

- Miller, D. (1996) A preliminary typology of organizational learning: synthesizing the literature, Journal of Management, 22(3): 485-505.

- Nahapiet, J., and Ghoshal, S., (1998), Social capital, intellectual capital, and the organizational advantage. Academy of Management Review, 23(2), 242266

- Narasimha, S. (2000) Organizational knowledge, human resource management, and sustained competitive advantage: toward a framework. Competitiveness Review, 10(1): 123-135.

- Ndlela, L.T., and Toit, A.S.A. (2001) Establishing a knowledge management programme for competitive advantage in an enterprise. International Journal of Information Management, 21: 151-165.

- Nelson, K.M., and Cooprider, J.G. (1996) The contribution of shared knowledge to IS group performance. MIS Quarterly, 20(4): 409-429

- Nevis, E.G., DiBella, A.J. and Gould, J.M. (1995), Understanding organizations as learning systems, Sloan Management Review, 36(2), pp. 7385 
- Nonaka, I. and Takeuchi, H. (1995), The Knowledge Creating Company: How Japanese Companies Create the Dynamics of Innovation, Oxford University Press, New York, NY.

- Nonaka, I., Toyama, R., and Konno, N. (2000) SECI, ba and leadership: a unified model of dynamic knowledge creation. Long Range Planning, 33(1): 5-34.

- O'Dell, C., and Grayson, J. (March/April 1999) Knowledge transfer: discover your value proposition. Strategy and Leadership, 27(2):10-15.

- Riggins, F. J., and Rhee, H. (1999) Developing the learning network using extranets. International Journal of Electronic Commerce, 4(1): 65-83.

- Roberts, J. (2000) From Know-how to show-how? Questioning the role of information and communication technologies in knowledge transfer. Technology Analysis and Strategic Management, 12(4): 429-443.

- Simonin, B. (1997) The importance of collaborative know-how: an empirical test of the learning organization. Academy of Management Journal, 40(5): 509-533

- Stonehouse, G.H., and Pemberton, J.D. (1999) Learning and knowledge management in the intelligent organization. Participation and Empowerment: An International Journal, 7(5): 131-144.

- Sveiby, K. 1997 The New Organization Wealth: Management and Measuring Knowledge-Based Assets. San Francisco: Berrett-Koehler Publishers,.

- Swan, J., Newell, S., and Robertson, M. January (2000) Limits of IT-driven knowledge management for interactive innovation processes: towards a community-based approach. Proceedings of the 33rd Hawaii International Conference on System Sciences,.

- Szulanski, G. (1996) Exploring internal stickiness: impediments to the transfer of best practice within the firm. Strategic Management Journal, 17(Winter): 27-43.

- Teagarden, M. B., Meyer, J., and Jones, D. (2008) Knowledge Sharing Among High-Tech MNCs in China and India: Invisible Barriers, Best Practices and Next Steps Organizational Dynamics, 37 (2), April-June 2008, Pages 190-202

- Teece, D.J. (2000) Strategies for managing knowledge assets: the role of firm structure and industrial context. Long Range Planning, 33(1): 35-54.

- Zaltman, G. (1986), Knowledge utilization as planned social change, in Beal, G., Dissanayake, W., Konoshima, S. (Eds),Knowledge Generation, Exchange and Utilization, Westview Press, Boulder, CO 
Table 1 Features of Codification and Personalization Strategies

\section{\begin{tabular}{l|l} 
Strategy & Features
\end{tabular}}

Codification

Emphasizes codified knowledge in knowledge management processes Stress on codifying and storing knowledge via information technology Attempt made to share knowledge formally

Personalization Emphasizes dialogue through social networks and person-to-person contacts Stress on acquiring knowledge via experienced and skilled people Attempt made to share knowledge informally 
Table 2 Frequency Distribution

\begin{tabular}{|c|c|c|c|c|c|c|}
\hline \multirow[t]{2}{*}{ Variable } & \multirow[t]{2}{*}{ Measurement } & \multicolumn{5}{|c|}{ Results (percent) } \\
\hline & & $\begin{array}{l}\text { Strongly } \\
\text { disagree }\end{array}$ & Disagree & Neural & Agree & $\begin{array}{l}\text { Strongly } \\
\text { agree }\end{array}$ \\
\hline \multirow{5}{*}{$\begin{array}{l}\text { Collaboration } \\
\text { (V1) }\end{array}$} & A: The organization members are satisfied with the degree of collaboration. & & 13.5 & 37.8 & 42.1 & 6.7 \\
\hline & B: The organization members are supportive to each other. & & 9.7 & 31.1 & 50.4 & 8.8 \\
\hline & C: The organization members are helpful. & & 6.5 & 31.5 & 49.6 & 12.4 \\
\hline & D: There is a willingness to collaborate across organizational units within the organization. & & 5.9 & 21.2 & 58.1 & 14.7 \\
\hline & E: There is a willingness to accept responsibility for failure. & & 5.9 & 38.7 & 49.3 & 6.1 \\
\hline \multirow[t]{6}{*}{ Trust (V2) } & A: Company members are generally trustworthy. & & 3.6 & 40.3 & 46.8 & 9.4 \\
\hline & B: Company members have reciprocal faith in other members' intentions and behaviours & & 8.1 & 34.2 & 52.9 & 4.9 \\
\hline & C: Company members have reciprocal faith in others' ability. & & 3.1 & 36.5 & 57.4 & 3.1 \\
\hline & D: Company members have reciprocal faith in others' behaviours to work toward organizational goals. & & & 41.7 & 55.2 & 3.1 \\
\hline & $\begin{array}{l}\text { E: Company members have reciprocal faith in others' decision toward organizational interests rather than individual } \\
\text { interests. }\end{array}$ & & 1.6 & 29.3 & 69.1 & \\
\hline & F: The company members relationships are based on reciprocal faith. & & 2.7 & 43.9 & 50.0 & 3.4 \\
\hline \multirow{5}{*}{ Learning (V3) } & A: The company provides various formal training programs related to performance. & 3.4 & 11.5 & 16.5 & 32.6 & 36.0 \\
\hline & B: The company provides opportunities for informal rather than formal training, e.g. work assignments and job rotation. & & 8.6 & 29.7 & 61.7 & \\
\hline & C: The company encourages people to attend seminars, symposia, etc. & 5.9 & 11.0 & 26.1 & 33.0 & 23.9 \\
\hline & D: The company provides various social programs such as clubs and community gatherings. & & 11.3 & 35.3 & 53.2 & .2 \\
\hline & E: Company members are satisfied with the job training or self-development programs. & & .4 & 34.9 & 52.5 & 12.2 \\
\hline \multirow{5}{*}{$\begin{array}{l}\text { Centralization } \\
\text { (V4) }\end{array}$} & A: Company members can take action without a supervisor. & 44.1 & 40.3 & 15.6 & & \\
\hline & B: Company members are encouraged to make their own decisions. & 2.0 & 30.8 & 37.9 & 29.3 & \\
\hline & C: Company members do not need to refer to someone else. & 4.1 & 25.9 & 47.5 & 22.5 & \\
\hline & D: Company members do not need to ask their supervisor before action. & 9.7 & 51.6 & 32.7 & 5.9 & \\
\hline & E: Company members can make decisions without approval. & 12.1 & 58.1 & 16.9 & 12.8 & .2 \\
\hline \multirow{4}{*}{$\begin{array}{l}\text { Formalization } \\
\text { (V5) }\end{array}$} & A: Many activities are not covered by formal procedures & 5.0 & 22.5 & 34.9 & 32.6 & 5.0 \\
\hline & B: Contacts with the company are on a formal or planned basis. & & 35.6 & 20.1 & 42.4 & 1.8 \\
\hline & C: Rules and procedures are typically written. & & 6.5 & 48.7 & 44.8 & \\
\hline & D: Members can ignore the rules and reach informal agreements when handling some situations & & 40.5 & 17.8 & 39.0 & 2.7 \\
\hline \multirow{5}{*}{ IT Support (V6) } & A: Company provides IT support for collaborative works regardless of time and place. & .4 & 4.3 & 25.4 & 56.7 & 13.3 \\
\hline & B: Company provides IT support for communication among organization members. & 2.5 & 13.5 & 10.3 & 48.2 & 25.5 \\
\hline & C: Company provides IT support for searching for and accessing necessary information. & & & 33.6 & 48.0 & 18.3 \\
\hline & D: Company provides IT support for simulation and prediction. & & 3.2 & 26.1 & 69.4 & 1.3 \\
\hline & E: Company provides IT support for systematic storing. & & 7.2 & 5.6 & 48.2 & 39.0 \\
\hline \multirow{7}{*}{$\begin{array}{l}\text { Organization } \\
\text { Performance (V7) }\end{array}$} & A: Compared with key competitors, the company is more successful. & 2.9 & 18.5 & 39.2 & 32.7 & 6.7 \\
\hline & B: Compared with key competitors, the company has a greater market share. & 14.9 & 14.0 & 24.1 & 36.3 & 10.6 \\
\hline & C: Compared with key competitors, the company is growing faster. & 14.7 & 21.2 & 24.8 & 35.6 & 3.6 \\
\hline & D: Compared with key competitors, the company is more profitable. & 14.7 & 15.6 & 23.7 & 37.2 & 8.6 \\
\hline & E: Compared with key competitors, the company is more innovative. & .2 & 15.6 & 25.5 & 54.7 & 4.0 \\
\hline & F: Compared with key competitors, the company is larger in terms of turnover. & 14.6 & 16.7 & 30.8 & 30.9 & 7.0 \\
\hline & G: Compared with key competitors, the company has more patents. & & 36.5 & 21.4 & 40.1 & 2.0 \\
\hline
\end{tabular}


Table 3 Variables Correlations Matrix

\begin{tabular}{lrrrrrrrr}
\hline & V7 & V1 & \multicolumn{2}{c}{ V2 } & V3 & \multicolumn{2}{c}{ V4 } & V5 \\
\hline V7 & 1.000 & .740 & .259 & .803 & .542 & .430 & .787 \\
V1 & .740 & 1.000 & .350 & .832 & .867 & .521 & .890 \\
V2 & .259 & .350 & 1.000 & .451 & .408 & .233 & .385 \\
V3 & .803 & .732 & .451 & 1.000 & .842 & .529 & .717 \\
V4 & .542 & .867 & .408 & .842 & 1.000 & .471 & .821 \\
V5 & .430 & .521 & .233 & .529 & .471 & 1.000 & .484 \\
V6 & .787 & .890 & .385 & .917 & .821 & .484 & 1.000 \\
\hline
\end{tabular}

\section{Table 4 Regression Test Results}

\begin{tabular}{|c|c|c|c|c|c|c|c|c|}
\hline \multicolumn{9}{|c|}{ Coefficients $^{a}$} \\
\hline \multirow{2}{*}{\multicolumn{2}{|c|}{ Model }} & \multicolumn{2}{|c|}{$\begin{array}{l}\text { Unstandardized } \\
\text { Coeff icients }\end{array}$} & \multirow{2}{*}{$\begin{array}{c}\text { Standardized } \\
\text { Coeff icients } \\
\text { Beta }\end{array}$} & \multirow[b]{2}{*}{$t$} & \multirow[b]{2}{*}{ Sig. } & \multicolumn{2}{|c|}{ Collinearity Statistics } \\
\hline & & $\mathrm{B}$ & Std. Error & & & & Tolerance & VIF \\
\hline \multirow[t]{7}{*}{1} & (Constant) & -2.256 & .276 & & -8.177 & .000 & & \\
\hline & V1: Collaboration & .175 & .100 & .120 & 1.750 & .008 & .097 & 10.264 \\
\hline & V2: Trust & .491 & .057 & .383 & 3.329 & .001 & .734 & 1.363 \\
\hline & V3: Learning & .990 & .094 & .778 & 10.531 & .000 & .083 & 11.995 \\
\hline & V4: Centralization & -.868 & .069 & -.563 & -12.595 & .000 & .227 & 4.397 \\
\hline & V5: Formalization & .029 & .033 & .023 & .892 & .373 & .714 & 1.401 \\
\hline & V6: IT support & .657 & .081 & .451 & 8.092 & .000 & .146 & 6.829 \\
\hline
\end{tabular}

a. Dependent Variable: V7: Organizational perf ormance

\section{Table 5 Summary of the Hypotheses Test Results}

\begin{tabular}{lllll} 
Hypotheses & $\begin{array}{l}\text { Expected } \\
\text { sign }\end{array}$ & Beta & t-value & $\begin{array}{l}\text { Support } \\
\text { for H? }\end{array}$ \\
\hline H1: Collaboration will have a positive effect on KM performance. & + & .120 & $1.750^{* *}$ & $\mathrm{Y}$ \\
\hline H2: Trust will have a positive effect on KM performance. & + & .383 & $3.329^{* *}$ & $\mathrm{Y}$ \\
\hline H3: Learning will have a positive effect on knowledge creation. & + & .778 & $10.531^{* *}$ & $\mathrm{Y}$ \\
\hline H4: Learning will have a positive effect on KM performance. & - & -.563 & $-12.595^{* *}$ & $\mathrm{Y}$ \\
\hline $\begin{array}{l}\text { H5: Centralization will have a negative effect on KM } \\
\text { performance. }\end{array}$ & - & .023 & .892 & $\mathrm{~N}$ \\
\hline $\begin{array}{l}\text { H6: Formalization will have a negative effect on the KM } \\
\text { performance. }\end{array}$ & + & .451 & $8.092^{* *}$ & $\mathrm{Y}$
\end{tabular}

$* * \mathrm{p}<0.01$ 


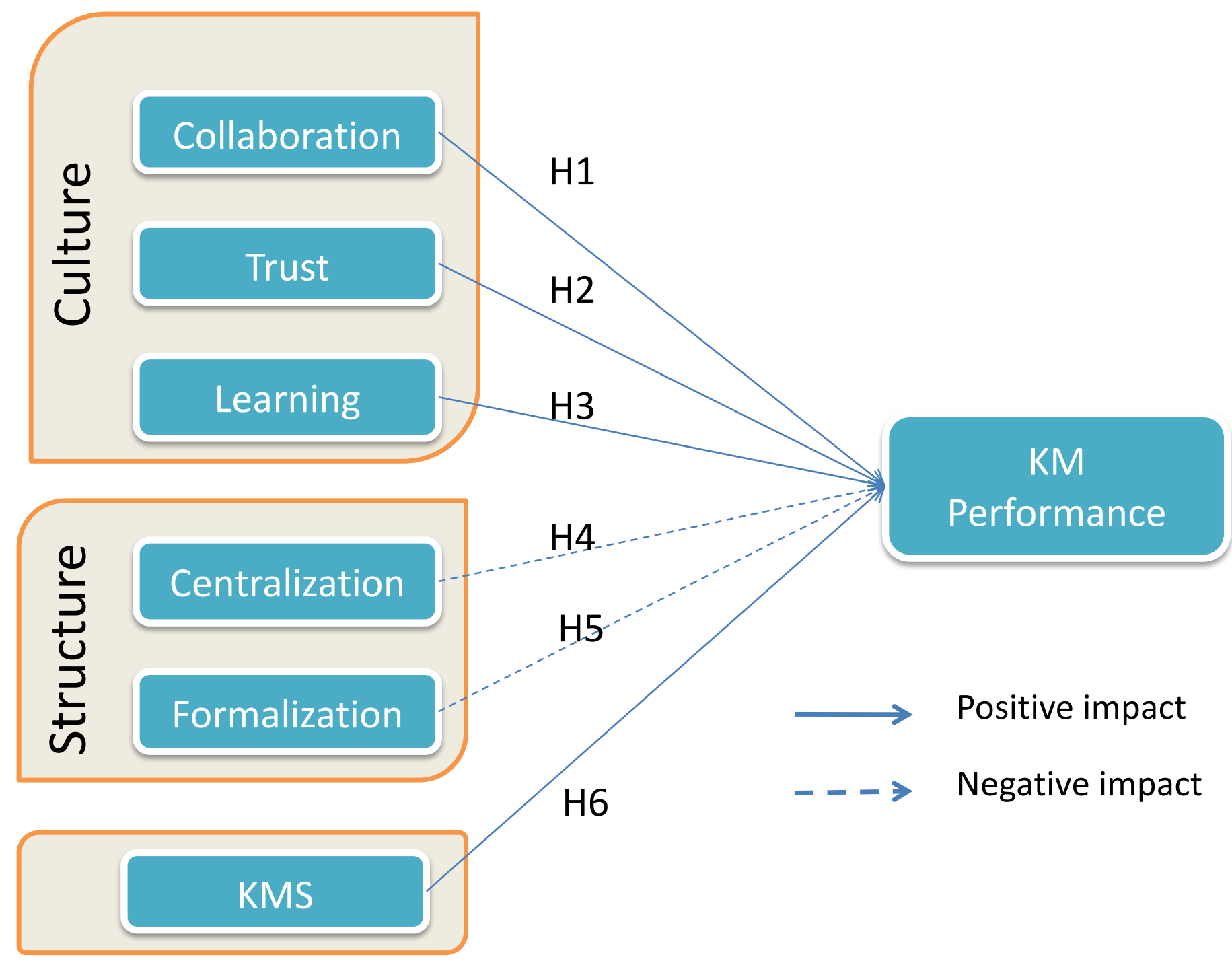

Figure 1 Integrated conceptual KM framework 